\title{
REGRAS, INCENTIVOS E COMPORTAMENTO: AS COMISSÕES PARLAMENTARES NOS PAÍSES DO CONE SUL
}

\author{
Marta Mendes da Rocha
}

\author{
Cássio Felipe Barbosa
}

\begin{abstract}
RESUMO
Este artigo analisa as tendências de funcionamento das comissões parlamentares das câmaras baixas em quatro países do Cone Sul: Argentina, Brasil, Chile e Uruguai. Parte-se do esquema que considera três tipos de variáveis: estruturais, procedimentais e as relativas ao poder das comissões. Procurou-se verificar os tipos de incentivos gerados pelas regras de organização legislativa em cada país: para a atuação clientelista, guiada pela lógica eleitoral, como defende o modelo distributivo; para a especialização, como prega o modelo informacional, ou para a realização dos interesses dos partidos, como propõe o modelo partidário. Conclui-se que todas as câmaras convivem com incentivos para os três tipos de comportamentos, evidenciando que os modelos não são excludentes e que a dinâmica legislativa é influenciada por outras variáveis, entre elas o padrão de relacionamento entre os poderes Executivo e Legislativo.
\end{abstract}

PALAVRAS-CHAVE: comissões; incentivos; regras institucionais; comportamento político; modelos de organização legislativa.

\section{INTRODUÇÃO}

Este trabalho tem como objetivo identificar as principais tendências que caracterizam a dinâmica do processo legislativo na Argentina, Brasil, Chile e Uruguai com foco nas comissões permanentes da Câmara Baixa. Pretende diagnosticar como o comportamento dos parlamentares é afetado pelas regras de organização legislativa e a qual modelo de organização legislativa - distributivista, informacional ou partidário - as câmaras analisadas mais se aproximam. O objetivo não foi testar as hipóteses apresentadas, mas desenvolver um modelo analítico que poderá servir de referência para futuras pesquisas na área. Trata-se, portanto, de uma análise exploratória, por meio da qual se pretende identificar as regras que influenciam o comportamento dos legisladores e inferir algumas tendências sobre a dinâmica legislativa nos quatro países. A partir da abordagem neo-institucionalista, o foco é deslocado das preferências para as instituições, acreditando ser possível inferir das regras e procedimentos da organização legislativa as “jogadas” permitidas e as mais atraentes, dados os incentivos institucionais fornecidos (pay-offs) (TSEBELIS, 1998; HALL \& TAYLOR, 2003).

A divisão do processo legislativo em sessões ou comissões buscou dotar de maior funcionali- dade e dinamismo os trabalhos legislativos que, a princípio, concentrados em um único órgão, mostravam-se lentos e superficiais (LEMOS, 2006, p. 157). Buscou ainda uma forma de oferecer respostas ao crescimento das atribuições do Estado, que se deu em vários países a partir da década de 1930, e à concomitante multiplicação dos temas e problemas tratados no âmbito do sistema político - conseqüências da diversificação e do aumento da complexidade social. Segundo Arrow (1963), ao estruturarem o trabalho legislativo em unidades menores, as comissões contribuem para solucionar alguns problemas de coordenação no processo de tomada de decisões e para dotar de maior estabilidade o jogo político. O autor afirma que uma decisão obtida exclusivamente por meio do voto seria inconsistente e indeterminada porque, a partir de uma confrontação pareada e exaustiva das alternativas em jogo, um ator sempre poderia encontrar uma situação mais favorável às suas preferências individuais (idem). Isso porque, ao se constituírem em unidades menores que o plenário, as comissões possibilitam a interação face a face entre seus membros e permitem empregar, para além do voto, outros métodos de tomada de decisão como a negociação e a deliberação. Ademais, afirma-se que as comissões constituem-se em arenas que possibilitam as minorias amplia- 
rem a sua influência sobre o processo legislativo, e aos legisladores, em geral, reduzirem a incerteza acerca da relação entre as políticas (meios) e seus resultados (fins). No contexto de processos decisórios que reservam ao poder Executivo importantes prerrogativas e recursos, como é o caso dos países analisados neste artigo, acredita-se que as comissões podem, ainda, oferecer à oposição melhores condições para o exercício efetivo de sua função de fiscalizar, pelo fato de que à oposição são reservadas prerrogativas para controlar os atos do poder Executivo (ANASTASIA, MELO \& SANTOS, 2004).

\section{MODELOS DE ORGANIZAÇÃO LEGISLA- TIVA}

Os estudos do Congresso norte-americano deram origem a três perspectivas analíticas distintas para a análise do processo legislativo: distributivista, informacional e partidária. Todas elas têm como premissa o individualismo metodológico. Partem da idéia de que os indivíduos agem buscando maximizar seus interesses e que os parlamentares, em particular, buscam em primeiro lugar assegurar a sua reeleição. Todavia, o padrão de comportamento e interação política (competitiva e cooperativa) dos mesmos dependerá das instituições, das condições e das preferências dos atores em jogo.

Sob a ótica distributivista (SHEPSLE, 1986; SHEPSLE \& WEINGAST, 1987), o processo legislativo caracteriza-se pela negociação em torno da alocação de benefícios políticos. As comissões são compreendidas como arenas que permitem aos parlamentares conquistarem ganhos de troca. Tratar-se-ia de uma relação de conflito na qual cada legislador tenta auferir o máximo de benefícios para a sua clientela às custas dos outros. Mas, dado que a intensidade com que os parlamentares preferem as suas alternativas não é igual, torna-se possível constituir uma espécie de "mercado de votos" no qual legisladores fazem concessões em matérias menos importantes para sua constituency, esperando que outros façam o mesmo em relação aos temas de relevância para os eleitores que representam (essa troca de votos é chamada pela literatura de logroll). Uma suposição desse modelo é a de que a forte conexão entre representantes e interesses geograficamente concentrados resultante de alguns sistemas eleitorais criaria incentivos para que os representantes atuassem primordialmente no sentido da promoção dos interesses de seu reduto eleitoral, guiando-se pelo paroquialismo, como forma de assegurar a sua reeleição.

Ainda sob o olhar distributivista, o sistema de comissões seria o eixo estruturador do processo legislativo porque permite "a ocorrência estável das trocas de apoio necessárias à aprovação de políticas distributivistas” tornado críveis os compromissos assumidos pelos legisladores (LIMONGI, 1998, p. 9). O sistema seria constituído de comissões homogêneas, mas não representativas do plenário, já que aquelas seriam compostas por membros com preferências extremas em relação ao tema em questão. Além disso, um pressuposto é de que o contexto de tomada de decisões caracterize-se pela existência de partidos fracos que não sejam capazes de constranger as escolhas de seus membros, caso contrário, os objetivos individuais dos parlamentares ver-se-iam ameaçados ${ }^{1}$.

Em diálogo direto com teoria distributivista, desenvolveu-se a abordagem informacional. Sua referência central é o trabalho de Krehbiel (1991). Um de seus postulados básicos é o da incerteza: o fato de que os parlamentares, ao tomarem suas decisões, não estão certos quanto à relação entre políticas e resultados e quanto aos resultados eleitorais de suas ações. Isso porque a informação e a especialização não são uniformemente distribuídas entre os atores do processo legislativo. Segundo Krehbiel, dado que os legisladores têm aversão a riscos, a redução da incerteza interessa a todos, sendo um bem coletivo. Por essa razão, diz o autor, o problema central para as legislaturas seria o de criar uma organização legislativa que permitisse aos legisladores tomarem decisões com base no maior volume possível de informações, oriundas de fontes diversas.

Outro postulado da abordagem informacional é o majoritário: a idéia de que as decisões tomadas em uma democracia, para serem coerentes com seus princípios balizadores - soberania popular e igualdade política - devem ser tomadas

\footnotetext{
1 Além da forma de composição das comissões, outro aspecto privilegiado pelos distributivistas refere-se às prerrogativas legislativas das comissões. Segundo eles, sendo obrigatória a passagem de todas as matérias pelas comissões, essas, com as prerrogativas legislativas concedidas pelo plenário, sobrepor-se-iam a ele no processo de tomada de decisões.
} 
pela maioria dos membros de uma legislatura. Nesse sentido, as comissões devem ser constituídas como microcosmos do plenário de modo que a distribuição de preferências nas comissões reflita a distribuição de preferências na casa legislativa. Dessa forma, as comissões seriam heterogêneas e contariam com a presença de membros de pólos opostos do espectro ideológico condição para que operem sobre uma base informacional plural. Somente assim se poderia esperar que o plenário concedesse vantagens legislativas às comissões. Isso porque, qualquer consenso alcançado na comissão poderia ser visto como representativo de um consenso possível no plenário e também porque os legisladores estariam certos de que as decisões tomadas nas comissões não se distanciariam muito das preferências dos membros da casa como um todo. De acordo com Krehbiel, o principal critério para a escolha de membros para as comissões seria a perícia (expertise): a capacitação prévia resultante de seu cabedal profissional. Segundo Santos e Almeida (2005), expertos (experts) são pessoas bem informadas a respeito de determinadas questões (issues) ou com grande potencial para aprender sobre as mesmas em função de sua formação escolar e/ou profissional e/ou de sua experiência prévia em cargos no poder Executivo, eletivos ou não. Krehbiel afirma que a perícia do legislador não determina suas preferências políticas já que expertos podem se situar em vários pólos do espectro ideológico. Além da presença de expertos, a legislatura precisa criar outros incentivos para a especialização dos legisladores como, por exemplo, a regra de antigüidade (seniority), praticada no Congresso norte-americano, segundo a qual os presidentes das comissões são os membros mais antigos do partido majoritário. Essa norma desestimula a troca de comissões e é um incentivo à especialização dos legisladores.

O resultado agregado da organização legislativa, segundo o modelo informacional, seria o fortalecimento do poder Legislativo. Este se tornaria um órgão com maior capacidade de analisar uma multiplicidade de temas e de produzir decisões e políticas mais bem fundamentadas. Por conseguinte, o resultado seria um maior equilíbrio entre os poderes. Seria razoável esperar, ainda, a formulação de uma agenda mais diversificada e a aprovação de políticas, em sua maioria, de cunho universalista.

Os modelos distributivista e informacional desconsideram os partidos em suas análises, dada a fragilidade dos mesmos na política norte-americana. Os autores do modelo partidário, à revelia, buscam reavaliar o papel das agremiações partidárias e a interação entre estas e as comissões (COX \& MCCUBBINS, 1993). Os autores assinalam que as comissões não são uma forma de organização legislativa que independe dos partidos, mas uma forma de governo partidário. Segundo eles, as comissões funcionariam como arenas que propiciam a promoção dos interesses partidários, sobretudo do partido majoritário - como espécies de cartéis legislativos. As lideranças partidárias seriam os atores centrais nesse processo, responsáveis pela elaboração da agenda do partido e pela busca de coesão no interior da agremiação.

QUADRO 1 - MODELOS DE ORGANIZAÇÃO LEGISLATIVA

\begin{tabular}{|c|c|c|c|}
\hline MODELO & DISTRBUTIVSTA & NFORMACKNAL & PARTIDÁRIO \\
\hline $\begin{array}{l}\text { Comissôes } \\
\text { conoebidas } \\
\text { como: }\end{array}$ & $\begin{array}{c}\text { Espapos de logrollque viabilizan } \\
\text { a aprovaça de políticas } \\
\text { dstributivistas. }\end{array}$ & $\begin{array}{l}\text { Espaços de especial zaçăo que } \\
\text { visam reduzir a incerteza ertre as } \\
\text { políticas e seus resuttados. }\end{array}$ & $\begin{array}{l}\text { Cartés legisativos: } \\
\text { espacos para a realizaçấo } \\
\text { dos interesses do partido, } \\
\text { solvetudo, o mejoritário. }\end{array}$ \\
\hline $\begin{array}{l}\text { Foma de } \\
\text { composiçấ das } \\
\text { comissóes }\end{array}$ & $\begin{array}{l}\text { Adto-seleção. Legisadores } \\
\text { escohen fazer pates das } \\
\text { comissốes que aumertan suas } \\
\text { dhanoes de reeleiçấo. }\end{array}$ & $\begin{array}{l}\text { Proporcionalmerte à distribuiçẫo } \\
\text { das preferências no plenátio / } \\
\text { ratificaçấo pelo plenário / critério da } \\
\text { pencía. }\end{array}$ & $\begin{array}{l}\text { Por meio da indicaç̃̃o das } \\
\text { lideranças partidasias, } \\
\text { segundo os interesses dos } \\
\text { partidos. }\end{array}$ \\
\hline $\begin{array}{l}\text { Perfil das } \\
\text { comissốes }\end{array}$ & $\begin{array}{c}\text { Nấo-represertativas do plenário } \\
\text { (mernbros com preferências } \\
\text { extremadas na área) / } \\
\text { homogêneas. }\end{array}$ & $\begin{array}{c}\text { Represertativas do plenário / } \\
\text { heterogêneas. }\end{array}$ & $\begin{array}{l}\text { Domiractas pelo patido } \\
\text { majoritário. }\end{array}$ \\
\hline $\begin{array}{l}\text { Caráter das } \\
\text { políticas }\end{array}$ & $\begin{array}{l}\text { Particuaristas / concertra } \\
\text { beneficio geograficamerte e } \\
\text { dispersa custos. }\end{array}$ & $\begin{array}{l}\text { Uriver salistas e Paticuaristas } \\
\text { (irteresses geográficos e de } \\
\text { grpos) }\end{array}$ & $\begin{array}{l}\text { Coerertes com a agenda } \\
\text { do partido majoritário. }\end{array}$ \\
\hline
\end{tabular}




\section{ANÁLISE COMPARATIVA}

O tema da reforma política, em maior ou menor grau, faz parte da agenda dos países objetos de análise. Direta ou indiretamente, os itens relacionados à reforma das instituições na Argentina, Brasil, Chile e Uruguai orientam-se pelo objetivo de fortalecer o poder Legislativo e equilibrar a relação entre os poderes de modo a aperfeiçoar a democracia. Há um consenso crescente de que o aprimoramento do trabalho nas comissões parlamentares é um caminho para que o poder Legislativo seja capaz de contrapor-se tecnicamente ao Executivo; especialmente para realizar as funções para as quais foi criado: representar os cidadãos, fiscalizar o governo e debater os problemas que afligem a sociedade.

Os estudos sobre os sistemas de comissões nos legislativos sul-americanos são ainda bastante recentes. No caso do Brasil, os poucos estudos evidenciam a dificuldade de se constatar um padrão de comportamento dos parlamentares partindo exclusivamente de um dos modelos apresentados. É possível encontrar nas regras de organização da Câmara dos Deputados incentivos para um comportamento ora distributivista, ora informacional ou ora partidário². Além disso, há autores que afirmam que as comissões da Câmara brasileira não estariam desempenhando qualquer papel relevante no processo legislativo, dada a concentração de prerrogativas nas mãos do poder Executivo (PEREIRA \& MUELLER, 2000).

A análise dos incentivos gerados pela organização legislativa na Argentina, Brasil, Chile e Uruguai aqui proposta foi realizada com base em informações obtidas nos regimentos internos das câmaras baixas e nas constituições dos respectivos países. Tomou-se como referência o esquema proposto por Santos (2000) que distingue três tipos de variáveis.

2 Em relação ao sistema de comissões da Câmara dos Deputados brasileira, destacam-se os trabalhos de Santos e Almeida (2005), Ricci e Lemos (2004), Pereira e Mueller (2000), Santos (2002) e Mueller (2005). Em relação aos demais países, destaca-se o trabalho de Montero e López (2002), no qual os autores realizam uma análise comparativa dos sistemas de comissões de 17 países latino-americanos a partir de uma perspectiva normativo-institucional e empírica.
O primeiro tipo de variáveis - estruturais refere-se ao número de comissões, à quantidade de membros de cada uma delas, e à existência ou não de restrição a participação do deputado em mais de uma comissão. Em relação a essas variáveis, o interesse foi identificar a capacidade da legislatura de analisar de forma mais aprofundada a variedade de temas objeto de legislação. Lemos (2006) supõe que, para isso, a organização legislativa deva permitir que todos os parlamentares participem das comissões e que, ao mesmo tempo, encontre-se um equilíbrio entre o número total de parlamentares da casa e o número de comissões em funcionamento. Nesses termos, impedir-se-ia que o trabalho das comissões tornasse-se contraproducente (LEMOS, 2006). Nesse sentido, limitar o número de comissões a que cada deputado pode participar seria uma forma de incentivar a especialização dos mesmos. Sem esse limite, e em presença de comissões muito grandes, os parlamentares podem encontrar dificuldades para especializarem-se e participarem efetivamente das discussões.

As variáveis procedimentais, segundo o tipo delimitado por Santos (2000), apontam para a forma como são escolhidos os membros das comissões. Dessa forma, esse trabalho pretende verificar se a distribuição de lugares nas comissões é feita proporcionalmente à distribuição dos partidos na casa, quais são os atores que detêm a prerrogativa de nomear membros para as comissões e a existência ou não de regras que incentivem a permanência em uma mesma comissão.

O terceiro tipo de variáveis diz respeito ao poder das comissões, no que concerne às suas prerrogativas e recursos legislativos vis-à-vis o plenário. Aqui, buscou-se verificar se às comissões é facultada a prerrogativa de iniciar legislação, emendar projetos do poder Executivo, controlar a tramitação dos mesmos e aprovar determinados projetos sem a necessidade de remetê-los ao plenário. Importou ainda observar se às comissões é facultado o direito de peticionar a autoridades e de propor e realizar eventos de interlocução com a sociedade civil organizada, como forma de ampliar sua base informacional.

No que se refere às variáveis estruturais, os países analisados apresentam as características esquematizadas no Quadro 2. 


\begin{tabular}{|c|c|c|c|c|}
\hline VARIÁVEL & ARGENTINA & BRASIL & CHILE & URUGUAI \\
\hline Tipos de comissốes & $\begin{array}{l}\text { Permanentes e } \\
\text { Temporárias } \\
\text { (especiais e de } \\
\text { investigaçẫo) } \\
\text { (Art. } 61 \text { e 104) }\end{array}$ & $\begin{array}{l}\text { Permanentes e } \\
\text { Temporárias } \\
\text { (especiais, de } \\
\text { inquérito ou } \\
\text { externas) } \\
\text { (Art. 22) }\end{array}$ & $\begin{array}{c}\text { Permanentes e } \\
\text { Temporárias (especiais, } \\
\text { investigadoras, unidas, } \\
\text { mistas e de acusaçãoo } \\
\text { constitucional) } \\
\text { (Art. 212) }\end{array}$ & $\begin{array}{c}\text { Permanentes e } \\
\text { Temporárias } \\
\text { (especiais) } \\
\text { (A.t. 114) }\end{array}$ \\
\hline Há subcomissỗes & Nẫo & Sim (Art. 29) & Sim (Art. 218) & Não \\
\hline $\begin{array}{l}\text { Número de } \\
\text { comissốes } \\
\text { permanentes }\end{array}$ & 45 (A.rt. 61) & 16 (Art. 32) & 19 (Art. 213) & 16 (Art. 115) \\
\hline $\begin{array}{l}\text { Número de membros } \\
\text { efetivos por } \\
\text { comissẫo } \\
\text { permanente }\end{array}$ & $\begin{array}{l}\text { Mínimo de } 15 \mathrm{e} \\
\text { máximo de } 31 \\
\text { (A.rt. 61) }\end{array}$ & $\begin{array}{l}\text { Entre } 17 \text { e } 61 \text {. (Art. } \\
25 \text { ) }\end{array}$ & 13 (Art. 213) & $\begin{array}{l}\text { Entre } 3 \text { e } 15 \\
\text { (Art. 115) }\end{array}$ \\
\hline $\begin{array}{l}\text { Existência de limite à } \\
\text { participaçẫo dos } \\
\text { deputados em } \\
\text { comissốes } \\
\text { permanentes }\end{array}$ & Nã̃o & Sim (Art. 26) & Nẫo & Não \\
\hline
\end{tabular}

FONTE: os autores.

Todos os países contam com comissões permanentes e temporárias. As primeiras fazem parte da estrutura institucional das câmaras e subsistem ao término da legislatura. As segundas são criadas para fins específicos e extinguem-se junto com a legislatura, ou antes, quando alcançado o fim a que se destinam ou quando expirado seu prazo de duração.

Salta aos olhos o número de comissões permanentes na Câmara Baixa argentina - muito superior ao dos outros países. No caso argentino observa-se um alto grau de divisão do trabalho legislativo e a existência de comissões voltadas exclusivamente para temas como interesses das mulheres e proteção dos direitos de crianças e adolescentes; idosos; legislação penal; prevenção e controle do narcotráfico; cooperativismo, associativismo e organizações não-governamentais, processo de integração regional, acusação política de autoridades púbicas; liberdade de expressão; e proteção às pessoas portadoras de ne- cessidades especiais. Em conjunto, as 45 comissões da Câmara argentina possuem 1258 lugares, o que significa que cada um dos 256 parlamentares argentinos deve participar de 4,9 comissões cada um, sem contar as comissões especiais.

Dos quatro países, apenas no Brasil é estabelecido um número máximo de comissões por deputado: cada parlamentar pode participar como membro titular de uma única comissão, com a ressalva da Comissão de Legislação Participativa e de Segurança Pública e Combate ao Crime Organizado. No Chile, estabelece-se um número fixo de membros por comissão. Na Argentina e no Uruguai esse número varia dentro de um limite pré-estabelecido, sendo que no segundo, o total de membros das comissões será igual ao total de membros da Câmara menos um.

No que se refere às variáveis procedimentais, os países analisados apresentam as características organizadas no Quadro 3.

QUADRO 3-VARIÁVEIS PROCEDIMENTAIS
\begin{tabular}{|l|c|c|c|c|}
\hline VARIÁVEL & ARGENTINA & BRASIL & CHILE & URUGUAI \\
\hline Composiçẫo das & Proporcionalmente & Proporcionalmente à & Proporcionalmente à & Nẵo faz mençẫo \\
comissóes & à distribuição e ao & distribuiçẫo e ao & distribuiçẫo e ao & \\
& peso dos partidos & peso dos partidos na & peso dos partidos na & \\
& na casa (Art. 105) & casa (Art. 25) & casa (Art. 213) & \\
\hline
\end{tabular}




\begin{tabular}{|c|c|c|c|c|}
\hline $\begin{array}{l}\text { Método de } \\
\text { indicaçã̃o de } \\
\text { membros para } \\
\text { as comissôes }\end{array}$ & $\begin{array}{l}\text { Indicaçẫo pela } \\
\text { Mesa / Indicaçẫo } \\
\text { dos membrosi } \\
\text { Eleiçẫo pelo } \\
\text { plenário (A.rt. 61) }\end{array}$ & $\begin{array}{c}\text { Indicação das } \\
\text { lideranças } \\
\text { partidárias e } \\
\text { posterior designação } \\
\text { pela Mesa Diretora } \\
\text { (A.r. 25) }\end{array}$ & $\begin{array}{l}\text { Aprovação pelo } \\
\text { plenário após } \\
\text { proposta da Mesa } \\
\text { (Art. 214) }\end{array}$ & $\begin{array}{c}\text { Indicação dos } \\
\text { delegados de cada } \\
\text { setor parlamentar } \\
\text { reunidos em uma } \\
\text { c omissấo especial } \\
\text { seguida de } \\
\text { designaçẫo pelo } \\
\text { Presidente da Mesa } \\
\text { (Art. 17) }\end{array}$ \\
\hline $\begin{array}{l}\text { Regra que } \\
\text { incentiva a } \\
\text { permanência do } \\
\text { parlamentar na } \\
\text { comissấo }\end{array}$ & $\operatorname{Sim}$ (A.rt. 107) & Nẫo & Nẫo & Nẫo \\
\hline
\end{tabular}

FONTE: os autores.

Com exceção do Uruguai, em todos os países analisados, os regimentos das casas legislativas estabelecem que as comissões devem ser compostas proporcionalmente à distribuição dos partidos na casa. No artigo 16 do regimento interno da Câmara uruguaia, assegura-se que, se no primeiro período de cada legislatura, depois da nomeação de parlamentares para as comissões, a composição da Câmara for modificada, designarse-á, a pedido de qualquer dos setores parlamentares, uma nova comissão especial para discutir a situação. Entretanto, o regimento não explicita se tal mecanismo visa, como no Brasil, evitar distorções entre a composição da Câmara e a das comissões, ou apenas manter os acordos firmados quando da composição das comissões no início da legislatura. A análise da distribuição de lugares no total da casa e no total das comissões, para a atual legislatura na Câmara argentina, brasileira e chilena, demonstra que a regra da proporcionalidade é seguida à risca.

Na Argentina, os membros das comissões são indicados pela Mesa segundo a configuração dos setores políticos representados na casa. O Presidente indica a forma de constituição que pode ser por eleição ou indicação dos membros, sobressaindo, portanto, a vontade do plenário ${ }^{3}$. No Brasil, a prerrogativa de indicar membros para as comissões é dos líderes partidários. No Chile os membros das comissões são eleitos pela Câmara via proposta da Mesa. No Uruguai, delegados dos diferentes setores parlamentares, reunidos em uma comissão especial, indicam os representantes para as comissões e, em seguida, considerando a indicação dos delegados, o Presidente da Mesa designa os membros. Observa-se, portanto, que, regimentalmente, em nenhum dos casos há auto-seleção de deputados para as comissões - condição para que as mesmas funcionassem segundo sugere o modelo distributivista.

A Câmara Baixa argentina é a única que oferece incentivos para a permanência do parlamentar em uma mesma comissão. Nesse país, o parlamentar tem a discricionariedade de permanecer na comissão por pelo menos um ano, mesmo contra a vontade dos líderes partidários.

As prerrogativas e recursos controlados pelas comissões, relativas à variável "poder das comissões” podem ser observadas no Quadro 4.

\begin{tabular}{|c|c|c|c|c|}
\hline TIPO DE PODER & ARGENTINA & BRASIL & CHILE & URUGUAI \\
\hline Iniciativa legislativa & Nẫo & $\operatorname{Sim}$ (Art. 109) & Nẵo & Nẵo \\
\hline Poder de emenda & $\operatorname{Sim}$ (Art. 111) & Sim (Art. 49) & $\operatorname{Sim}$ (Art. 129) & $\operatorname{Sim}($ Art. 142) \\
\hline $\begin{array}{l}\text { Prazo para o plenário } \\
\text { apreciar o parecer da } \\
\text { comissấo }\end{array}$ & $\begin{array}{l}\text { Sim, no caso de "moción } \\
\text { de preferencia" } \\
\text { (A.rt. 132) }\end{array}$ & Nẫo & Nã̃o & Nã̃o \\
\hline
\end{tabular}

3 Segundo Oliveira (2006), a indicação pelo presidente tende a favorecer o partido majoritário. Já segundo Men- donça (2005), a exigência de eleição pelo plenário tende a fazer que a vontade deste prevaleça na constituição das comissões. 


\begin{tabular}{|lcccc|}
\hline Poder terminativo & $\begin{array}{c}\text { Apenas em casos } \\
\text { excepcionais (Art. 79 } \\
\text { CF) }\end{array}$ & Sim (Art. 54) & Nẫofaz mençẫo & Nẫo \\
$\begin{array}{l}\text { Peticionar a } \\
\text { autoridades }\end{array}$ & Sim (Art. 204) & Sim (Art. 24) & Sim (A.rt. 293) & Nẫo \\
$\begin{array}{l}\text { Interlocução coma } \\
\text { sociedade }\end{array}$ & $\begin{array}{c}\text { Audiências públicas, } \\
\text { fóruns e vídeo-chat } \\
\text { (Art. 114 bis) }\end{array}$ & $\begin{array}{c}\text { Audiências } \\
\text { públicas } \\
\text { (Art. 24) }\end{array}$ & $\begin{array}{c}\text { Audiências públicas e } \\
\text { Jornadas Temáticas } \\
\text { (Art. 218 bis) }\end{array}$ & Nẫo \\
\hline
\end{tabular}

FONTE: os autores.

A leitura do quadro permite constatar que apenas no Brasil as comissões têm a prerrogativa de iniciar legislação. Nos demais países, os projetos de lei devem ser de autoria de um parlamentar individual. Nos quatro casos analisados, as comissões podem emendar os projetos enviados à sua apreciação. No Brasil, as comissões podem apreciar um projeto conclusivamente em casos específicos, podendo o plenário barrá-lo por recurso de um décimo dos deputados. Na Argentina, esse poder é mais restrito: somente em casos excepcionais o plenário pode delegar à comissão, por deliberação da maioria absoluta dos deputados e após análise do projeto em votação, o direito de apreciar conclusivamente uma proposição ${ }^{4}$. Os regimentos das câmaras chilena e uruguaia não fazem menção a tal dispositivo.

Com exceção do Uruguai, nos demais países as comissões podem peticionar a autoridades públicas, incluindo ministros de estado e membros da administração pública, para prestar esclarecimentos. Na Argentina, os pareceres das comissões, no caso das "mociones de preferencia”, devem ser apreciados pelo plenário no prazo de dez dias, passados os quais o parecer será considerado automaticamente aprovado. Os regimentos das demais casas não fazem menção a uma regra semelhante.

O regimento interno da Câmara Baixa chilena prevê que, nos casos de projetos que não tenham recebido pedido de urgência, as comissões devem realizar uma audiência de pelo menos uma hora de duração para ouvir as instituições e entidades que tenham interesse na matéria a que se refere o projeto (Art. 211 do regimento interno). Além disso, o regimento prevê a realização de duas “jornadas temáticas” dentro de cada período legislativo, com o objetivo de ouvir os cidadãos interessados no tema em questão. No Brasil, prevê-se a realização de audiências públicas com a participação da sociedade civil. Na Argentina, as comissões poderão realizar audiências públicas e abrir fóruns e video-chat de debates virtuais com a finalidade de conhecer a opinião da cidadania em geral, pessoas jurídicas - de caráter público ou privado - e organizações da comunidade sobre matérias sobre sua competência. Apenas na Câmara uruguaia não há menção sobre a existência de mecanismos de interlocução das comissões com a sociedade civil.

\section{PRERROGATIVAS DO PODER EXECUTIVO}

Sabendo-se que, em maior ou menor grau, os presidentes sul-americanos possuem importantes poderes para influenciar o processo legislativo, é importante identificar as prerrogativas e recursos controlados pelo poder Executivo em cada país (Quadro 5) para se avaliar a efetividade das variáveis relativas ao poder das comissões.

\begin{tabular}{|c|c|c|c|c|}
\hline PRERROGATNAS & ARGENTINA & BRASIL & CHILE & URUGUAI \\
\hline Decreto com força de lei & Sim & Sim & $\begin{array}{c}\text { Poder delegado de } \\
\text { decreto }\end{array}$ & Sim \\
\hline Decreto constitucional & Sim & Sim & Nẫo & Sim \\
\hline Iniciativa exclusiva & Nã̃o & Sim & Sim & Sim \\
\hline $\begin{array}{l}\text { Monopólio de envio de matéria } \\
\text { orçamentária }\end{array}$ & Sim & Sim & Sim & Sim \\
\hline Veto total e parcial & Sim & Sim & Sim & Sim \\
\hline Pedido de urgência & Nẫo & Sim & Sim & Sim \\
\hline
\end{tabular}

FONTE: Anastasia, Melo e Santos (2004)

\footnotetext{
4 A delegação pode ser revogada pela deliberação da maio-
} ria absoluta dos deputados. 
O quadro permite verificar que no Brasil e no Uruguai o poder Executivo conta com todas as principais prerrogativas legislativas e não legislativas. Em conjunto, essas prerrogativas oferecem ao Executivo a possibilidade de influenciar o processo decisório, predominar em determinadas áreas da legislação, determinar a agenda e o ritmo do processo legislativo e manipular as preferências dos legisladores a seu favor de modo a aprovar sua agenda ${ }^{5}$. A prerrogativa do pedido de urgência tem sido apontada por vários estudiosos como a principal responsável pela fragilidade das comissões parlamentares no Brasil (PEREIRA \& MUELLER, 2000). Tal mecanismo é um obstáculo para que as comissões funcionem seguindo o modelo informacional, uma vez que os projetos são retirados das mesmas antes que seus membros tenham chance de examiná-los e discuti-los de forma aprofundada. Ademais, há ainda, no caso brasileiro, a existência da instituição do colegiado de líderes que centraliza ainda mais o processo decisório ao concentrar nas mãos das lideranças partidárias importantes poderes de agenda. Segundo Pereira e Mueller (2000), quando é pedida urgência na tramitação de um projeto, as comissões têm apenas duas sessões para examiná-lo e votálo antes de enviá-lo para o plenário. De acordo com o artigo 54 do regimento da Câmara, além do Presidente, o pedido de urgência pode ser feito por dois terços da Mesa Diretora, por um terço dos membros do plenário ou líderes que representem esse número e por dois terços do membro da comissão. A análise do uso dessa prerrogativa mostra que ela é mais comum em se tratando de projetos de lei iniciados pelo poder Executivo e que, em sua maioria, os pedidos foram feitos pelo próprio Congresso. Dessa forma, observa-se que é o uso dessa prerrogativa pelos próprios parlamentares que cria obstáculos ao trabalho das comissões impedindo-as de analisar de forma aprofundada as proposições.

Para vários autores, a organização legislativa da Câmara dos Deputados brasileira não oferece incentivos diretos à permanência dos parlamenta-

\footnotetext{
5 A preponderância legislativa do poder Executivo é um tema amplamente debatido na ciência política brasileira. O trabalho de referência é o de Figueiredo e Limongi (1999), que mostra como os presidentes brasileiros sobrepõem-se ao legislativo no processo decisório valendo-se das prerrogativas e recursos que tem ao seu dispor e da força das lideranças partidárias no interior do parlamento.
}

res nas comissões ou à sua especialização, como ocorre com a regra da antiguidade no congresso norte-americano. Ao contrário, observa-se, nas comissões, um alto grau de rotatividade que, segundo Pereira e Mueller (2000), cria obstáculos para que as comissões funcionem, seja de acordo com a abordagem informacional, seja de acordo com a abordagem distributivista, porque dificultam a especialização e deixam de prover compromissos críveis para realização dos ganhos de troca.

Ainda sobre a prerrogativa da urgência observa-se que, no Uruguai, a legislatura pode derrubar o pedido de urgência pelo voto de três quintos do total de membros, caso em que o projeto volta a tramitar normalmente.

No Chile o Presidente não possui a prerrogativa de emitir decretos constitucionais, mas possui todas as demais prerrogativas, incluindo o pedido de urgência. Na Argentina, também existe a instituição do Colégio de Líderes, mas o Presidente não possui a prerrogativa de iniciativa exclusiva e de pedido de urgência. Em suma, a análise das prerrogativas e recursos controlados pelo poder Executivo identificados no Quadro 5 permite afirmar que essas são mais amplas no Brasil, Uruguai, Chile e Argentina, nessa ordem. Os efeitos do uso de tais prerrogativas e recursos, no entanto, não podem ser deduzidos de sua simples existência, devendo-se considerar outras variáveis como a distribuição de preferências no poder Legislativo, o tamanho da coalizão de apoio ao Presidente, entre outras.

\section{V.CONCLUSÕES}

Como afirmado no início da sessão anterior, os três modelos de organização legislativa não são excludentes e é possível encontrar numa mesma casa legislativa características de todos eles, notadas algumas particularidades. A coexistência de características dos modelos distributivista, informacional e partidário pode ser evidenciada nas câmaras baixas dos quatro países analisados.

Não é possível encontrar nas regras que norteiam o funcionamento das comissões parlamentares na Câmara Baixa argentina incentivos para uma dinâmica do tipo distributivista. O sistema eleitoral é de lista fechada e, portanto, não favorece uma forte identificação entre representantes e representados e não permite afirmar que os primeiros orientemse exclusiva ou primordialmente pelo interesse de sua constituency. Em tese, tal sistema tenderia a 
favorecer o fortalecimento dos partidos na arena decisória. Todavia, no que concerne às comissões, as lideranças partidárias não detêm a prerrogativa de indicar membros para preenchê-las. Elas são compostas por meio de eleição pelo plenário e proporcionalmente à distribuição dos partidos no mesmo, o que sugere que as comissões espelhem a distribuição de preferências da casa.

O sistema argentino conta com regras que podem ser consideradas como incentivos para uma atuação pró-ativa e consistente das comissões na produção legislativa. Entre elas, pode-se assinalar: a existência do poder de emenda das comissões, a possibilidade de apreciar conclusivamente algumas matérias, a existência de prazo para o plenário apreciar os informes das comissões, o poder de peticionar a autoridades públicas, a existência de mecanismos de interlocução com a sociedade e a ausência da prerrogativa do Presidente de pedir urgência na apreciação de projetos de lei. Esta última sugere que na Câmara argentina, comparativamente aos demais países analisados, as comissões tenham maior controle sobre a tramitação das proposições. Tais características, somadas à composição proporcional das comissões e à regra que estimula a permanência dos representantes nas mesmas, podem ser vistas como importantes incentivos para uma produção legislativa mais informada, com a presença de especialistas e baseada numa matriz plural de preferências e perspectivas. Por outro lado, há características que ameaçam criar obstáculos ao trabalho das comissões e dificultar o surgimento de especialistas para a produção informada de leis. São elas: o número elevado de comissões, o tamanho das comissões e a ausência de limite à participação dos deputados.

O sistema de comissões brasileiro, por seu turno, também convive com diferentes incentivos institucionais que o torna compatível com os três modelos de organização legislativa. O sistema eleitoral de listas abertas favorece uma forte conexão entre os parlamentares e seus representantes, o que embasaria a hipótese distributivista. Por outro lado, sabe-se que as regras que norteiam o processo decisório reservam importantes poderes às lideranças partidárias, entre eles, o de designar membros para as comissões, embasando a hipótese partidária. Assinala-se, ainda, que a limitação do número de comissões de que cada parlamentar pode participar, assim como a composição proporcional das mesmas, seriam incentivos para seu funcionamento seguindo o modelo informacional. Sob essa lógica, as comissões forneceriam uma arcabouço plural de informações para a negociação e a deliberação legislativas, possibilitando a formação de especialistas.

Não é possível estabelecer uma lógica inequívoca de funcionamento das comissões. Não obstante, pode-se constatar os fatores que favorecem a sua atuação pró-ativa no processo decisório e fatores que impedem que as comissões desempenhem adequadamente a sua função. Entre as primeiras, assinalam-se: os poderes de iniciativa legislativa e emenda, a possibilidade de apreciar conclusivamente matérias, de peticionar a autoridades públicas e os mecanismos de interlocução com a sociedade. Já entre as segundas, destacamse: o tamanho das comissões (entre 25 e 51 participantes), a ausência de regras que incentivem a permanência do legislador na comissão e que impeçam a alta rotatividade dos mesmos, e a prerrogativa do Presidente e das lideranças partidárias de pedir urgência na tramitação das leis.

A Câmara Baixa chilena, no que se refere às variáveis estruturais e procedimentais, parece oferecer condições favoráveis a uma atuação informacional das comissões: um número pequeno de comissões se comparada à Câmara argentina; comissões pequenas compostas de 13 parlamentares (o que favorece a participação individual e a coordenação dos trabalhos); composição proporcional à distribuição das preferências no plenário e submetida à aprovação desse. As comissões chilenas possuem poder de emenda, poder de peticionar a autoridades e de realizar eventos de interlocução com a sociedade. Por outro lado, elas também convivem com obstáculos a uma atuação mais pró-ativa, sendo a principal a concentração de prerrogativas em torno do poder Executivo, entre as quais destaca-se o pedido de urgência.

O sistema eleitoral uruguaio é proporcional e de lista fechada. Como se afirmou para o caso argentino, tal sistema não favorece uma relação próxima entre representantes e representados, tendendo a fortalecer os partidos ${ }^{6}$. A indicação de membros para as comissões é prerrogativa dos delegados dos setores parlamentares, seguido de decisão da Mesa Diretora, o que sugere que as lideranças partidárias têm influência na escolha das

6 Mainwaring e Shugart (1999) destacam que a existência das listas sobrepostas no caso uruguaio não favorece a 
comissões nas quais pretendem possuir membros. A Câmara Baixa uruguaia possui um número de comissões igual ao do Brasil e próximo ao do Chile, comissões que podem ser consideradas pequenas se comparadas às comissões argentinas e brasileiras.

Entretanto, o que poderia ser visto como um quadro favorável à especialização, à participação ativa dos parlamentares no processo legislativo e a uma produção bem informada de políticas, torna-se menos promissor quando se analisam as variáveis relativas ao poder das comissões. Das quatro câmaras analisadas, a uruguaia é a que oferece menos prerrogativas e recursos às suas comissões. Paralelamente, possui um poder Executivo que, assim como o brasileiro, conta com todas as prerrogativas listadas.

A análise das regras de organização legislativa das câmaras baixas na Argentina, Brasil, Chile e Uruguai corrobora a idéia de que as mesmas convivem com incentivos para os três modelos de organização legislativa, capazes de alimentar, simultaneamente, diferentes dinâmicas decisórias. Embora a análise realizada permita descortinar algumas tendências na dinâmica de operação dos legislativos examinados, foca apenas as condições necessárias para uma atuação pró-ativa e informacional dos mesmos. Essas condições não são, de forma alguma, suficientes. A avaliação do papel desempenhado pelas comissões no processo legislativo dos países em foco deve passar pela análise de outras variáveis não consideradas nesse trabalho como, por exemplo, os critérios utilizados para distribuir os parlamentares pelas comissões. Estes podem ser alocados de acordo com seu próprio interesse em alocar benefícios para sua constituency (modelo distributivista), de acordo com sua perícia (modelo informacional) ou de

centralização partidária, mas sim as facções partidárias sendo, portanto, um sistema mais desconcentrado do que o sistema puro de listas fechadas. acordo com os interesses do partido (modelo partidário). Os regimentos, embora estabeleçam a quem pertence a prerrogativa de indicar membros para as comissões, não informam como se dá, na prática, a alocação dos parlamentares e os critérios adotados para tal. Além disso, seria importante verificar como são escolhidos os presidentes e relatores das comissões. Embora o método mais comum para a escolha dos presidentes seja a eleição pelos membros da comissão, alguns autores têm chamado a atenção para as negociações envolvendo a escolha de presidentes e relatores de comissões (SANTOS \& ALMEIDA, 2005). Para eles esta é uma forma pela qual o poder Executivo tenta ampliar seu controle sobre o processo legislativo: negociando cargos em comissões estratégicas. Também seria importante verificar a existência de regras que asseguram a participação das minorias legislativas nas comissões, os procedimentos de tomada de decisão e a distribuição de prerrogativas no interior das comissões (direito de voz, voto, forma de tramitação de projetos, entre outros).

Outro dado importante que não foi considerado no presente estudo é a existência ou não de assessorias institucionalizadas de apoio às comissões. Sabe-se que estas são importantes para tornar mais informacional o processo decisório na medida em que suprem os legisladores das informações relevantes para a tomada de decisões sobre uma determinada política. Ademais, é uma forma pela qual os legislativos vêm ampliando sua capacidade de lidar com uma variedade de temas e, com isso, tentando contrapor-se tecnicamente ao poder Executivo. No tocante aos legislativos caracterizados por alto grau de renovação, como o brasileiro, a existência de assessorias institucionalizadas é também uma forma de assegurar um arcabouço informacional permanente à disposição dos legisladores. Acredita-se que a adição dessas variáveis às já elencadas neste artigo seja um ponto de partida promissor para futuras investigações sobre as comissões parlamentares dos legislativos da região.

Marta Mendes da Rocha (mendesrocha@ufmg.br) é Mestre e Doutoranda em Ciência Política pela Universidade Federal de Minas Gerais (UFMG) e Pesquisadora do Centro de Estudos Legislativos da mesma instituição.

Cássio Felipe Barbosa (cfbarbosa@terra.com.br) é Mestrando em Ciência Política pela Universidade Federal de Minas Gerais (UFMG) e pesquisador do Centro de Estudos Legislativos da mesma instituição. 


\section{REFERÊNCIAS BIBLIOGRÁFICAS}

ANASTASIA, F.; MELO, C R. F. \& SANTOS, F. 2004. Governabilidade e representação política na América do Sul. São Paulo : UNESP.

ARROW, K. 1963. Social Choice and Individual Values. $2^{\text {nd }}$ ed. New York : Viley.

COX, G. W. \& MCCUBBINS, M. D. 1993. Legislative Leviathan. Party Government in the House. Berkeley : University of California.

FIGUEIREDO, A. M. C. \& LIMONGI, F. 1999. Executivo e Legislativo na nova ordem constitucional. Rio de Janeiro : FGV.

GILLIGAN, T. W. \& KREHBIEL, K. 1987. Collective Decision-Making and Standing Committees : An Informational Rationale for Restrictive Amendment Procedures. Journal of Law, Economics and Organization, Oxford, v. 3 , n. 5, p. 287-335.

HALL, P. A. \& TAYLOR, R. C. R. 2003. As três versões do neo-institucionalismo. Lua Nova, São Paulo, n. 58, p. 193-224.

KREHBIEL, K. 1991. Information and Legislative Organization. Ann Arbor : University of Michigan.

LEMOS, L. B. 2006. El sistema de comisiones en el Senado brasileño : jerarquía y concentración de poderes en la década de 1990. América Latina Hoy, Salamanca, n.43, p. 155-182.

LIMONGI, F. 1994. O novo institucionalismo e os estudos legislativos : a literatura norte-americana recente. BIB, Rio de Janeiro, n 37, p. 3-38.

MAINWARING, S. \& SHUGART, M. 1999. Presidentialism and Democracy in Latin América. Cambridge, UK : Cambridge University.

MENDONÇA, L. 2005. Accountability e estratégias procedimentais no interior das comissões : Brasil e Argentina em perspectiva comparada. Teoria e Sociedade, Belo Horizonte, número especial, p. 94-137.

MONTERO, M. G. \& LÓPEZ, F. S. 2002. Las comisiones legislativas en América Latina : una clasificación institucional y empírica. Working Papers ICPS n. 212. Barcelona : Institut de Ciències Polítiques i Socials. Disponível em : http://americo.usal.es/oir/legislatina/papers/ ICPS212.pdf. Acesso em : 3.maio.2008.
MUELLER, G. 2005. Comissões e partidos políticos na Câmara dos Deputados : um estudo sobre os padrões partidários de recrutamento para as comissões permanentes. Dados, Rio de Janeiro, v. 48, n. 1, p. 371-394.

O’DONNELL (ed.). 1988. Transições do regime autoritário. São Paulo : Vértice.

OLIVEIRA, L. H. H. 2006. Presidencialismos em perspectiva comparada : Argentina, Brasil e Uruguai. Dados, Rio de Janeiro, v. 49, n. 2, p. 301-343.

PEREIRA, C. \& MUELLER, B. 2000. Uma teoria da preponderância do poder Executivo : o sistema de comissões no Legislativo brasileiro. Revista Brasileira de Ciências Sociais, São Paulo, v. 15, n. 43, p. 45-67.

RICCI, P. \& LEMOS, L. B. 2004. Produção legislativa e preferências eleitorais na Comissão de Agricultura e Política Rural da Câmara dos Deputados. Revista Brasileira de Ciências Sociais, São Paulo, v. 19, n. 55, p. 107-130.

SHEPSLE, K. A. 1986. The Positive Theory of Legislative Institutions : An Enrichment of Social Choice and Spatial Models. Public Choice, n. 50, p. 135-178.

SHEPSLE, K. A. \& WEINGAST, B. R. 1987. The Institutional Foundations of Committee Power. American Political Science Review, Washington, D. C., n. 81, p. 85-103.

SANTOS, F. 1997. Patronagem e poder de agenda na política brasileira. Dados, Rio de Janeiro, v. 40 , n. 3.

2002. Partidos e comissões no presidencialismo de coalizão. Dados, Rio de Janeiro, v. 45, n. 2, p. 237-264.

2003. Partidos e comissões no presidencialismo de coalizão. O poder Legislativo no presidencialismo de coalizão. Belo Horizonte : UFMG.

SANTOS, F. \& ALMEIDA, A. 2005. Teoria informacional e a seleção de relatores na Câmara dos Deputados. Dados, Rio de Janeiro, v. 48 , n. 4 , p. 673-735.

TSEBELIS, G. 1998. Jogos ocultos : escolha racional no campo da política comparada. São Paulo : USP. 


\section{OUTRAS FONTES}

ARGENTINA. 1996a. Constituición nacional. Buenos Aires : Honorable Cámara de Diputados de la Nación Disponível em : http:// www.diputados.gov.ar/. Acesso em : 3.mar.2008.

1996b. Reglamento interno de la honorable Câmara de Diputados de la Nación. Buenos Aires : Honorable Cámara de Diputados de la Nación. Disponível em : http:// www.diputados.gov.ar/. Acesso em : 3.mar.2008.

BRASIL. 1988. Constituição da República Federativa do Brasil. Brasília : Senado Federal.

BRASIL. CÂMARA DOS DEPUTADOS. 2006. Regimento interno da Câmara dos Deputados. Brasília : Câmara dos Deputados. Disponível em : http://www2.camara.gov.br/legislacao/ regimentointerno.html. Acesso em : 3.mar.2008.

CHILE. 2008a. Constituición Política de la Re- pública de Chile. Disponível em : http:// www.camara.cl/legis/constitucion/ cP_2008.pdf. Acesso em : 3.mar.2008.

2008b. Reglamento interno de la Cámara de Diputados de Chile. Santiago : Cámara de Diputados de Chile. Disponível em : http:// www.camara.cl/legis/down/rcd_07.pdf. Acesso em : 3.mar.2008.

URUGUAY. 2004. Constituición nacional de la República Oriental del Uruguay. Disponível em : http://pdba.georgetown.edu/Constitutions/ Uruguay/uruguay04.html. Acesso em : 3.mar.2008.

2008. Reglamento Interno de la Cámara de Representantes de la República Oriental el Uruguay. Montevideo : Cámara de Representantes de la República Oriental Del Uruguay. Disponível em : http:// www.parlamento.gub.uy/dgip/IndexDB/ Leyes/ConsultaLeyes.asp. Acesso em : 3.mar.2008. 
RULES, INCENTIVES, AND BEHAVIOR: PARLIAMENTARY COMMISSIONS IN SOUTHERN CONE COUNTRIES

\section{Marta Mendes da Rocha and Cássio Felipe Barbosa}

ABSTRACT: This article analyzes tendencies regarding the way parliamentary commissions work at the lower House levels in four Southern Cone countries: Argentina, Brazil, Chile and Uruguay. Our point of departure is a framework that considers three types of variables: structural, procedural and those related specifically to the power that the commissions themselves hold. We have attempted to verify what types of incentives have been generated by each country's rules of legislative organization: for clientelist actions guided by electoral logical, as advocated by the distributive model; for specialization, as the information model advocates, or for the fulfillment of party interests, as the political party model proposes. We have concluded that all the houses provide some space for all three types of behavior, thus indicating that these models are not mutually exclusive and that legislature dynamics are influenced by other variables among which patterns of Executive-Legislative relationships figure prominently.

KEYWORDS: commissions; incentives; institutional rules; political behavior; models of legislative organization.

\section{RÈGLES, INCENTIFS ET COMPORTEMENT: LES COMMISSIONS PARLEMENTAIRES DANS LES PAYS DU CÔNE SUD}

\section{Marta Mendes da Rocha et Cássio Felipe Barbosa}

Cet article analyse les tendances de fonctionnement des commissions parlementaires des chambres basses dans quatre pays du Cône Sud : Argentine, Brésil, Chili et Uruguay. Nous nous appuyons sur le schéma à trois types de variables : structurales, procédurales et celles liées au pouvoir des commissions. Nous avons cherché à vérifier les types d'incentifs issus des règles d'organisation législative dans chaque pays : pour l'action clientéliste, orientée par la logique électorale, comme préconise le modèle distributif ; pour l'action spécialisée, comme prône le modèle informationnel, ou pour la réalisation des intérêts des partis, comme propose le modèle des partis. Nous concluons que toutes les chambres cohabitent avec des incentifs issus des trois types de comportement, ce qui met en évidence que les modèles ne sont pas contradictoires et que la pratique législative subit l'influence d'autres variables, entre elles le modèle de rapport entre les pouvoirs Exécutif et Législatif.

MOTS-CLÉS : commissions ; incentifs ; règles institutionnelles ; comportement politique ; modèles d’organisation législative. 